\title{
India Moves Towards Menstrual Hygiene: A Key Challenge
}

\author{
Aditi Sengar $^{1}$ and Anil Kumar Agarwal ${ }^{1 *}$ \\ Department of Community Medicine, GR Medical College, India \\ Received: 海 August 23, 2018; Published: 䟧 August 28, 2018 \\ *Corresponding author: Anil Agarwal, Medical College Campus G. R. Medical College, Gwalior (M.P.) 474009, India
}

\section{Minini Review}

Author has been recently passed from a terrific experience when they started to clean the empty plot for making a house. It was seen a lot of sanitary napkin and clothes used for menstrual period directly or wrapped in news papers was dumped in that open plot. It means even now no community planning and awareness in relation to sanitation and disposal of menstrual materials. Menstrual hygiene management (MHM) relates to how girls and women manage their monthly period, and require access to information about menstruation, clean and safe menstrual absorbents, and amenities and facilities such as toilets and water, and waste management to maintain hygiene. In India, menstruation is surrounded by myths and misconceptions with a long list of "do's" and "don'ts" for women. Even though menstruation is a natural process, it is associated with misconceptions, malpractices and challenges among women in developing countries. Menstruation has always been surrounded by different perceptions throughout the world.

Nowadays, there is some openness toward menstruation, but differences in attitude still persist between different populations [1] There are many taboos like menstruating women is prevented from going to temple, to cook food, to attend weddings, etc. There is limited knowledge and many misconceptions about menstruation among women in India. This usually leads to undue fear, anxiety, and undesirable practices [2]. It was observed in our study that lack of infrastructure to dispose of used cloths and pads is the main cause for practicing the cloth in place of disposable pads because it was found easy to use and wash the cloth with soap after use. In our study regarding the method of disposal of the used material, most of the women (56.75\%) reused cloth pieces and only $41.5 \%$ women have knowledge regarding properly disposed the used material. Menstrual Hygiene Management (MHM) is a challenging issue among women and girls. Until now, issues about menstruation have been considered taboo and an abomination in several cultures and societies.

Menstruating women and girls are often are viewed or described as dirty, impure, unclean, unhygienic, and contaminated and are forced to suffer restriction, rejection, embarrassment, and in some cultural settings are prevented from taking part in cultural and religious gatherings and house chores. However, only girls of younger than 10 year (having not yet gone through puberty) and women older than 50 year (after menopause) are allowed to make the pilgrimage in addition to men. All menstruating women regardless of age are prohibited from observing the pilgrimage prayers and entering the temple3. Unfortunately, 58.5\%womens were ignorant about menstrual material disposal in our study. But, each and every woman should be aware about menstrual hygiene \& menstrual material disposal. This gap might be due to poor literacy and socio-economic status of women as well as lack of infrastructure and awareness regarding menstrual material disposal, which have fueled the inhibitions a woman has to talk to investigator regarding the significance, hygienic practices and a healthy attitude towards menstruation.

During investigation many types of comments and opinions suggested and disclosed by women in different strata, e.g. Appropriate disposal of used menstrual material is still lacking in many countries of the world. Because of lack of menstrual management practices in the world, most of the women dispose of their sanitary pads or other menstrual articles into domestic solid wastes, open field area or garbage bins that ultimately become a part of solid wastes. Toilet facilities in India lack bins for the disposal of sanitary pads and hand washing facilities for menstruating women to handle menstrual hygiene. In urban areas, where modern disposable menstrual products are used they dispose of them by flushing in toilets and throwing in dustbins or through solid waste management4.Reproductive tract infections, which has become a silent epidemic that devastates women's life is closely interrelated with poor menstrual hygiene. Therefore, proper menstrual hygiene and correct perceptions and beliefs can protect the womenfolk from this suffering.

Researches confirm that with safe menstrual hygienic practices women were less vulnerable to reproductive tract infections (RTIs)2. The lack of attention to this issue is striking as still we cannot achieve several Millennium Development Goals (MDGs), that is [2-5] and 5B. The MDG 2, achieving universal 
primary education and MDG 3 on promoting gender equality and empowering women are vital for achieving almost all the other MDGs5. Hygiene-related practices of women during menstruation are of considerable importance, as it may increase vulnerability to Reproductive Tract Infections (RTI's). Poor menstrual hygiene is one of the major reasons for the high prevalence of RTIs in the country and contributes significantly to female morbidity. In order to eliminate needless limitations in relation to menstruation a number of changes are required in women's social and reproductive health situation, community planning in relation to sanitation and disposal, and product development. If the economic stature of India is changing as a whole, women's situation with regard to menarche and menstruation may also change in the same direction.

\section{ISSN: 2574-1241}

DOI: $10.26717 / B J S T R .2018 .08 .001652$

Anil Agarwal. Biomed J Sci \& Tech Res

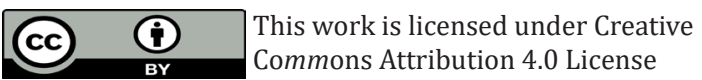

Submission Link: https://biomedres.us/submit-manuscript.php

\section{References}

1. Cronje HS, Kritzinger IE (1991) Menstruation: symptoms, management and attitudes in university students. Int J Gynaecol Obstet 35(2):147-50.

2. Mahon T, Fernandez M (2010) Menstrual hygiene in South Asia: a neglected issue for WASH (water, sanitation and hygiene) programmes. Gender Dev 18(1): 99-113.

3. (2018) Entry of women in Kerala's Sabarimala temple: 'Everyone can go,' says Supreme Court.

4. Rajanbir Kaur, Kanwaljit Kaur, Rajinder Kaur (2018) Menstrual Hygiene, Management, and Waste Disposal: Practices and Challenges Faced by Girls/Women of Developing Countries. Journal of Environmental and Public Health Volume 2018.

5. Sangeeta Kansal, Sweta Singh, Alok Kumar (2016) Menstrual Hygiene Practices in Context of Schooling: A Community Study among Rural Adolescent Girls in Varanasi. Indian J Community Med 41(1): 39-44.

$\begin{array}{ll}\text { BIOMEDICAL } & \text { Assets of Publishing with us } \\ \text { RESEARCHES } & \text { - Global archiving of articles } \\ & \text { - Immediate, unrestricted online access } \\ & \text { - Rigorous Peer Review Process } \\ \end{array}$

